\title{
Variations in the feeding habits of males and females of the crab Sesarma intermedia
}

\author{
Joel Kyomo \\ Dept of Zoology and Marine Biology, University of Dar es Salaam, PO Box 35064, Dar es Salaam, Tanzania
}

\begin{abstract}
Feeding habits were compared between males and females from 3 or 4 populations of Sesarma intermedia de Haan (Crustacea; Grapsidae) in western Japan. Females had higher indices of stomach contents than males. However calorific values of the contents were greater for males than for females. These differences seemed to be explained by differences in food preferences between males and females; this was substantiated by the food materials identified in the foreguts. Males had much more unidentified material in their foreguts than females, which had more plant food material. Females are thus more specialized in feeding than males which may be considered to be more generalist. In laboratory experiments, soil substrate food was ingested by both males and females more than plant food. Females, however, showed higher assimilation efficiencies than males for both food types.
\end{abstract}

\section{INTRODUCTION}

Crustaceans are a successful group in terms of both number of living species and colonization of different habitats. Their habitats include benthic environments of the deep oceans, coastal and estuarine regions, and semiterrestrial, terrestrial and freshwater environments of ponds and lakes. Crabs include filter feeders, detritus feeders, plant and carrion feeders, scavengers and predators and many of them use more than one method of feeding and various sources of food (Sastry 1983).

Among others, the parameter energy content of food has been suggested to be used when considering the evolution of food preferences in animals (Schoener 1971). The important characteristic of food choice is probably related not only to the calorific value of the food, but also to its composition, availability, easiness in handling and probably efficiency of digestion (Paine \& Vadas 1969, Carefoot 1973). Apparently, the supply of food per se is not a limiting factor for animals that eat plants because rarely are herbivores seen to eat more than a fraction of the plants available to them. Individual animals feed selectively not only on particular species of plants but on certain parts of plants. This selection is for the tissue with the highest nitrogen content (White 1978). Low $\mathrm{N}$ supplies invariably result in increased consumption rates and prolonged periods of feeding (Mattson 1980).
There are few studies on Sesarma intermedia (de Haan) explaining its ecological distribution and reproduction (Hashiguchi \& Miyake 1967, Fukui \& Wada 1986, Kyomo 1986, 1988) and its daily rhythmic activities (Yoshida 1961, Kyomo 1986). With the exception of studies on Uca spp. (Ocypodidae), not much work has been published on sexual dimorphism in feeding habits of Crustacea (Valiela et al. 1974). In the present work I describe the differences between males and females of $S$. intermedia with respect to food procurement. Food preferences, food quality and food items are examined on a comparative basis.

\section{MATERIALS AND METHODS}

The study was carried out in 1987 on the coasts of Kyushu Island, Western Japan. The study sites were Ariake (Upper, Middle and Lower) and Hakata (Tatara), described in Kyomo (1986, 1988).

Quantitative stomach content index. Sesarma intermedia is fully active from May onwards after 6 mo of hibernation. However, depending on annual temperature fluctuations, this active phase may begin as early as April. The crabs are most active when precipitation and humidity are high with optimum temperatures of $25^{\circ} \mathrm{C}$. On fine days, the most active times are before sunrise and after sunset. At night and during the day, they are less or not active (Kyomo 1986). 
Samples were taken monthly from March to September 1987 on successive fixed dates at 3 sites: Ariake Lower, Ariake Middle and Tatara. Random sampling in $10 \times 10$ m quadrats was done after sunset from 17:30 to 18:30 h. Only active and fully appendaged individual males and females were taken. Newly moulted and chelipedless individuals were avoided. Individuals collected during March to May were immediately killed with dry ice. Summer samples were killed with ordinary ice and both categories were immediately processed in the laboratory. Ten to twenty individuals of each sex ranging in size between 18.5 and $31.5 \mathrm{~mm}$ carapace width $(\mathrm{CW})$ (mean $=25.5 \mathrm{~mm}$ ) were examined. Dissection was done from the dorsolateral margin through the 'front' carapace which was then lifted anteriorly to expose the inner organs. Cutting the epithelium of the foregut exposed the contents. The stomach contents were removed with forceps and placed into pre-weighed aluminium foil containers. Bodies without gut contents and containers with contents were then oven-dried at $80^{\circ} \mathrm{C}$ for $24 \mathrm{~h}$ and the monthly quantitative stomach index (QSI) determined from the relationship

$$
\mathrm{QSI}=\frac{1}{n} \cdot \sum_{i=1}^{n} \frac{\varepsilon}{\varepsilon+W} \times 100
$$

where $\varepsilon=$ dry weight of stomach contents; $W=$ total dry weight of body without stomach contents; and $n=$ number of individuals.

Food type. Samples for this observation were collected once a week during the active period and time (see above) Altogether about 200 individuals of both sexes were dissected. Collections were made at Ariake (Middle and Lower) and Tatara. Treatment of the crabs was as above. Food types in the foreguts were identified with the aid of a microscope. The amount of particular food items was estimated on a 0 to 5 point scale, from zero for an empty stomach up to 5 for a full stomach.

Calorific values of stomach contents. Dried stomach contents and crab bodies used to calculate stomach content indices were preserved in dessicators for later calorific determinations. Aliquots of ground bodies and samples of stomach contents were weighed to $0.1 \mathrm{mg}$ and the energy equivalents in calories were determined by a Digital Calorimeter (Type OSK 200) standardized with benzoic acid.

Assimilation efficiency. Five to six males and a similar number of nonovigerous females from each of the study sites were sampled in August. Crabs were placed in separate boxes in a compartmental incubator set at $25^{\circ} \mathrm{C}$. Feces were collected every day at a fixed time and the inside of the boxes cleaned of any traces of feces on the surfaces using a moistened paper towel. The crabs were starved until no more feces were produced.
Each group was then supplied with a weighed sample of wet mortar and pestle ground young leaves of Phragmites communis as food, collected from the respective area of each group and placed into Petri dishes. Crabs were left to feed on this diet for $24 \mathrm{~h}$ during and after which feces were collected and unconsumed leaves weighed. When defecation ceased, the feces were air-dried, pooled for each group and weighed. The second diet was a substratum soil (a thin layer of soil 1 to $2 \mathrm{~mm}$ deep) again collected from the group's respective area. The same procedure as for plant food was followed. The experiment was repeated so that each group ate each of the diet types twice in succession. Each time the diet was supplied, a control of that particular food type was set aside in a separate box for determination of percent weight loss due to evaporation.

The amount of food material eaten was calculated in $g$ ind. ${ }^{-1} d^{-i}$. The amount of food consumed, less the weight of feces and the weight loss due to evaporation was taken as the assimilation portion. Both defecated and assimilated material portions were expressed as percentages of the raw food suppiy.

\section{RESULTS}

\section{Quantitative Stomach Index}

Feeding activity apparently starts as soon as the crabs emerge after the long hibernation period. This was indicated by the presence of fresh food material in the foreguts of the initial samples in March (Fig. 1). It is also

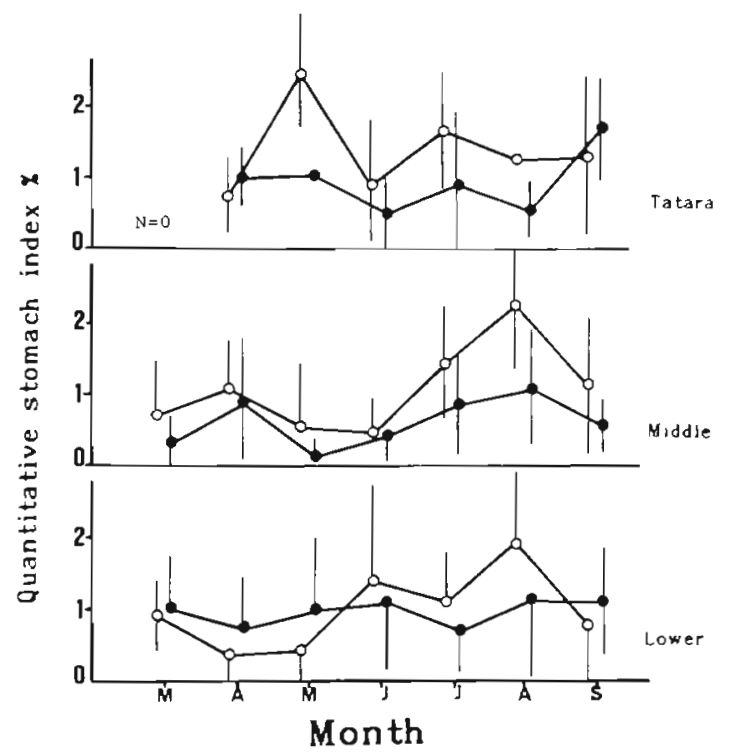

Fig. 1. Sesarma intermedia. Feeding activity as QSI tor males (-) and females (o). Vertical lines indicate $95 \%$ confidence limits of the mean 
clear from this figure that the beginning of annual activity differs between populations. No active individuals could be found from the Tatara population when the first sampling was taken. However, females of this population had the highest QSI in April. (Observations from one site, Ariake Upper, are excluded from these results because the site was destroyed by construction of a bridge while the data were being collected.) It is noticeable that in any one population, females had higher QSIs than males throughout the active period. An exception was, however, observed for the Lower site population from March to May during which females had lower feeding rates than males. It may be of relevance here that the Lower site had the lowest $\mathrm{N}$ concentrations in both the plant food and substratum (Kyomo unpubl.).

\section{Food type}

Results from observations of food materials in the foreguts are shown in Fig. 2. Altogether 65 individuals of both sexes had empty foreguts while 12 males and only 4 females had unidentified food materials. About 110 individuals had plant food material (Phragmites communis) in their guts, over half of which were almost full (scale point 4). This plant species was the most common at all the study sites. The plant is probably the main food material of Sesarma intermedia, which is mostly herbivorous.

\section{Calorific values of stomach contents}

A summary of the results on calorific values of food materials in the foregut is shown in Fig. 3. During any one month (except May), calorific values for male stomach contents were higher than for females.

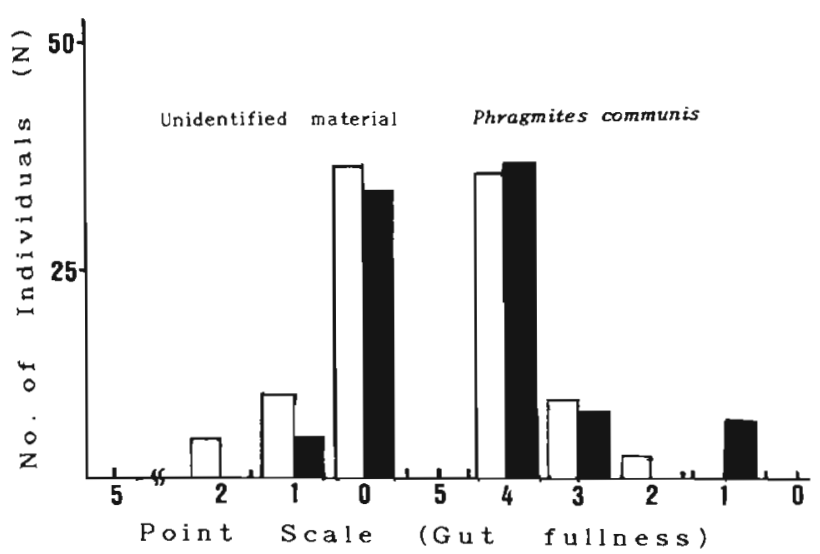

Fig. 2. Sesarma intermedia. Stomach content analysis for males (open bars) and females (black bars)

\section{Assimilation efficiency}

Both males and females ingested 2 to 3 times more substrate food than green leaves of Phragmites communis (Fig. 4). Females ingested $2.5 \mathrm{~g} \mathrm{~d}^{-1}$ of the substrate against $2 \mathrm{~g} \mathrm{~d}^{-1}$ ingested by males. About $0.65 \mathrm{~g}$ $\mathrm{d}^{-1}$ and $0.8 \mathrm{~g} \mathrm{~d}^{-1}$ of the plant were ingested by females and males respectively. Female assimilation efficiency was higher than that of males for both foods. About $85.2 \%$ of the substrate material was assimilated by females and $70.4 \%$ by males. Likewise, $82.7 \%$ of the plant food provision was assimilated by females and only $66.5 \%$ by males.

\section{DISCUSSION}

Most Grapsidae, including the sub-family Sesarmidae, are omnivorous with a tendency toward herbivory (Cott 1929, Hiatt 1948, Seiple \& Salmon 1982).

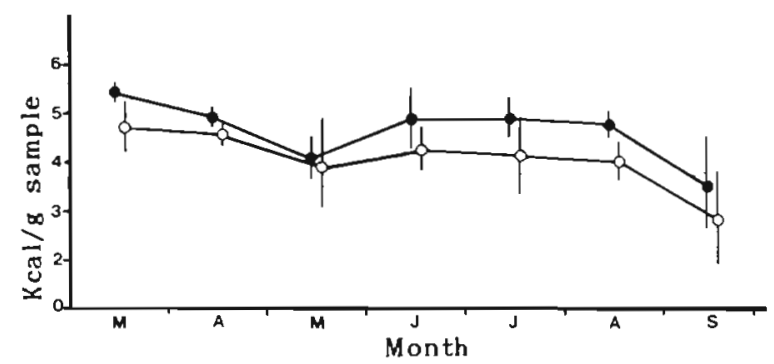

Fig. 3. Sesarma intermedia. Calorific values of stomach contents. (o) Females; $(\bullet)$ males. Bars are \pm SD of the mean
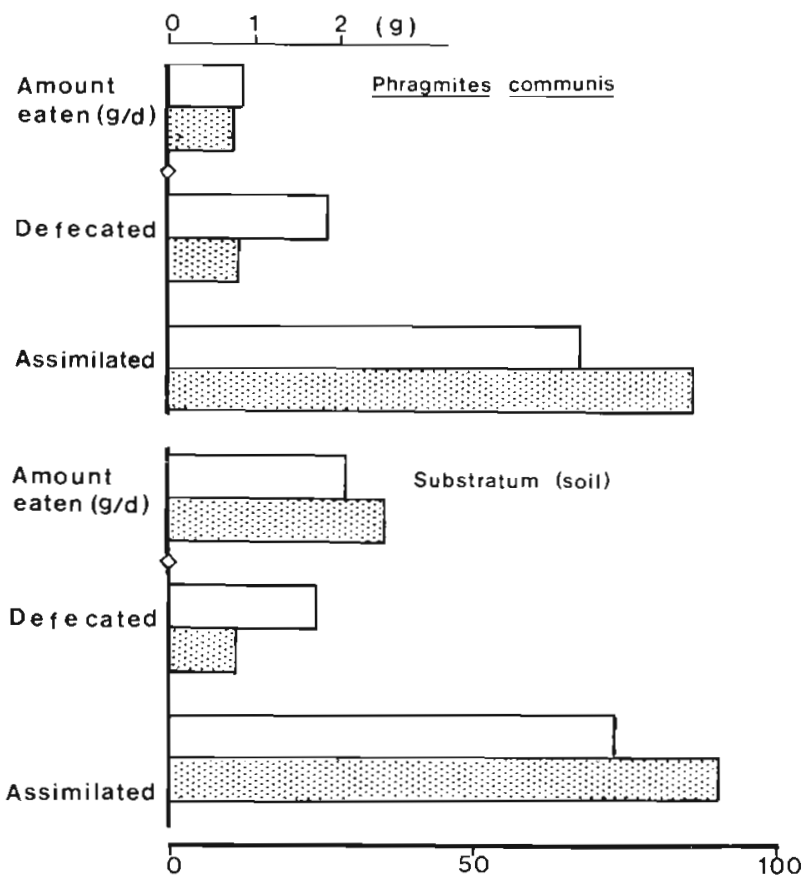

Fig. 4. Sesarma intermedia. Assimilation efficiencies of food materials. Shaded bars: females; open bars: males 
Stomach content analyses showed that plant material (Phragmites communis) comprised a larger proportion than other, unidentifiable, materials (Fig. 2). Of these foregut contents, females had eaten more plant food while most of the unidentified materials were found in the male foreguts. Several other crabs have been found to be feeding on a wide variety of food substances. Hill (1976) found that about $65 \%$ of Scylla serata had identifiable materials, mostly gastropod remains, in their foreguts.

As much as 80 to $90 \%$ of leaf material eaten by terrestrial detritus feeders is returned to the environment in the form of feces (Bärlocher \& Kendrick 1975). Malley (1978) reported that more than $95 \%$ of the stomach content analysed in the sesarmid Chiromanthes onychophorum consisted of leaf fragments which are consumed as litter and degraded, and much of which is released back to environment as fine fecal pellets. Diatoms and nematodes were taken in smaller quantities. It is suggested here that there is a great need for flexibility and caution in making conclusions on food habits and types in animals. A population occupying an environment with less palatable flora, tor example, may be better adapted to forage on fauna present in its vicinity than another population of the same genus or species in a different habitat. Some species may be predominantly herbivorous like Cardisoma guanhumi, which was reported to feed on more than 30 species of plants (Herreid 1963), Sesarma reticulatum and $S$. cinereum (Seiple \& Salmon 1982), and Chiromanthes onychophorum (Malley 1978), while Sesarma erythrodactylum was found to be omnivorous (Hara \& Ono 1976). In the present study, higher consumption of the substrate soil than of plant material does not necessarily mean that crabs prefer this food item over plant material in nature, but may have been due to the condition of the food supply. As the plant leaves were finely ground, they had lost their 3-dimensional structure and were therefore difficult to handle. As the experimental crabs were starved and the food types given alternately, feeding on naturally appearing substance may have been enhanced. Crabs usually cut plant leaves into defined rectangular pieces before taking them to the buccal cavity. An alternative explanation is that grinding of the leaves might have produced too much aroma which reduced their consumption rate. Although the consumption of the substrate was twice as much as that of the plant food, the 2 food types were assimilated in almost equal amounts. Much of the substrate was therefore defecated, indicating that, in nature, a plant resource is prefered over other food materials

The feeding habits in an Ocypodidae, Uca pugnax, showed that females have 2 feeding appendages while males use only one. One cheliped in males is enlarged and functions in courtship behaviours. Females showed feeding motions (by chelae) twice as many times as males during a fixed period (Valiela et al. 1974). In Grapsidae, Sesarma intermedia is conspicuous in showing dimorphism, both chelipeds being hypertrophied in males. Both chelae are used for feeding in both males and females. One would expect males, with larger chelae, to have higher feeding rates and therefore higher stomach content indices than females. No functional adaptation of the enlarged chelae, other than for digging larger burrows (Kyomo 1986), has been reported in this species. Interestingly, however, the present observations showed that feeding rates are higher in females than in males (Fig. 1). Laboratory feeding experiments show that both females and males ingested the substratum soil 2 to 3 times more than plant food. Percentage assimilation efficiency figures were within the range of those of other invertebrates (e.g. Grahame 1973) and females had higher assimilation efficiencies than males. Likewise, females of Asellus aquaticus showed a higher assimilation efficiency than males (Prus 1971), and in a shrimp, Branchinecta gigas, efficiency of females was $94 \%$ and that of males was only $64 \%$ (Darbon 1975). These findings, however, should be interpreted with caution due to inherent shortcomings of the methods - the handling of food items by crabs in nature and in the laboratory could greatly vary, the digestion of food by starved crabs could differ from the digestive process in nature, and low food availability in the field could affect the results.

These results seem to suggest that males and females of Sesarma intermedia have different nutritional demands and food processing. Males spend much time during the active period on mating behaviours (e.g. digging larger burrows), and therefore less on feeding. The hypertrophied chelae are probably used also for clasping females larger than themselves during mating (Kyomo 1986). Feeding seems to be compensated by selecting more nutritious food items. Males were observed to be moving longer distances from the burrow areas during the active phase. The duration of activity, where 'active' is defined as the situation when the crab is out of the burrow, is however the same between males and females (Kyomo 1986). The difference in the calorific values of the stomach contents indicates selective feeding by males. The possibility that males are more selective and females are more specialized feeders is a hypothesis which needs further investigation.

Acknowledgements. I am very grateful to Profs. Y Ono and M. Murai of the Laboratory of Animal Ecology, Kyushu University, for their assistance during the study. I also thank Prof. F. Kasule (University of Dar es Salaam) for his critical review of the manuscript. 


\section{LITERATURE CITED}

Bärlocher, F., Kendrick, B. (1975). Assimilation efficiency of Gammarus pseudolimnaeus (Amphipoda) feeding on fungal mycelium or autumn leaves. Oikos 26: 55-59

Carefoot, T. H. (1973). Feeding, food preference and uptake of food energy by the supralittoral isopod Ligia plasil. Mar. Biol. 18: 228-236

Cott, H. B. (1929). Observations on the natural history of the land crab Sesarma meinerti. Proc. Zool. Soc. Lond. 3-4: 679-692

Darbon, G. (1975). Life history and energy relations of the giant fairy shrimp Branchinecta gigas (Crustacea: Anostracta). Ecology 56: 1025-1039

Fukui, Y., Wada, K. (1986). Distribution and reproduction of four intertidal crabs in Tonda river estuary, Japan. Mar. Ecol. Prog. Ser. 30: 229-241

Grahame, J. (1973). Assimilation efficiency of Littorina littorea (Gastropoda). J. Anim. Ecol. 42: 383-389

Hashiguchi, Y., Miyake, S. (1967). Ecological studies on marsh crabs Sesarma spp. Habitats, copulation and egg bearing season II. Science Bulletin of the Fact. of Agr. Kyushu Univ. 23(2): $67-80$

Hara, M., Ono, Y. (1976). The daily movement and feeding activity of a sesarmid crab Sesarma erythrodactylum in salt marshes. Publ. Amak. Mar. Biol. Lab. 4: 21-40

Hiatt, R. W. (1948). The biology of the lined shore crab Pachygrapsus crassipes. Pacif. Sci. 2: 135-213

Herreid, C. F. II (1963). Observations on the feeding behaviour of Cardisoma guanhumi (Latreille) in South Florida. Crustaceana 5: 176-180

Hill, B. J. (1976). Natural food, foregut clearance-rate and activity of the crab Scylla serrata. Mar. Biol. 34: 109-116

Kyomo, J. (1986). Reproductive activities of the sesarmid crab

This article was submitted to the editor
Sesarma intermedia in coastal and estuarine habitats. Mar Biol. 91. 316-329

Kyomo, J. (1988). Analysis of the relationship between gonads and hepatopancreas in males and females of the crab Sesarma intermedia with reference to resource use and reproduction. Mar Biol. 97: 87-93

Malley, D. F. (1978). Degradation of the mangrove leaf litter by the tropical sesarmid crab Chiromanthes onychophorum. Mar Biol. 49: 377-386

Mattson, W J. Jr (1980). Herbivory in relation to plant nitrogen content. Ann. Rev. Ecol. Syst. 11: 119-161

Paine, R. T., Vadas, R. L. (1969). Calorific values of benthic marine algae and their postulated relations to invertebrate food preference. Mar. Biol. 4: 79-86

Prus, T (1971). The assimilation efficiency of Asellus aquaticus (Crustacea: Isopoda). Freshwat. Biol. 1: 287-304

Sastry, A. N. (1983). Ecological aspects of reproduction. In: Bliss, D. (ed.) The biology of crustaceans, Vol. 8. Academic Press, New York, p. 179-267

Schoener, T. W (1971). Theory of feeding strategies. Ann. Rev. Ecol. Syst. 2: 369-404

Seiple, W., Salmon, M. (1982). Comparative social behaviour of two grapsid crabs Sesarma reticulatum and S. cinereum. J. exp. mar. Biol. Ecol. 62: 1-24

Valiela, I., Babiec, D. F., Antherton, W., Seitzinger, S., Krebs, C. (1974). Some consequences of sexual dimorphism: feeding in male and female fiddler crabs Uca pugnax (Smith). Biol. Bull. 147: 652-660

White, T. C. R. (1978). The importance of relative shortage of food in animal ecology. Oecologia (Berl.) 33: 71-86

Yoshida, M. (1961). Daily rhythmic activities of a land crab, Sesarma intermedia. Jap. J. Ecol. 11. 160-162 (In Japanese; English summary)

Manuscript first received: October 9, 1990

Revised version accepted: April 28, 1992 